Gut, 1989, 30, 1362-1370

\title{
Respiratory burst activity of intestinal macrophages in normal and inflammatory bowel disease
}

\author{
Y R MAHIDA, K C WU, AND D P JEWELL \\ From the Gastroenterology Unit, Radcliffe Infirmary, Oxford
}

SUMMARY Macrophages isolated from normal mucosa (greater than $5 \mathrm{~cm}$ from tumour) and inflamed mucosa (from patients with inflammatory bowel disease) of colon and ileum were studied for their ability to undergo a respiratory burst as assessed by reduction of nitroblue tetrazolium to formazan. Using phorbol myristate acetate (PMA) and opsonised zymosan as triggers, only a minority (median: $8 \%$ for zymosan and 9\% for PMA) of macrophages isolated from normal colonic mucosa demonstrated release of oxygen radicals. In contrast, a significantly greater (median: $17 \%$ for zymosan and $\mathbf{4 5 \%}$ for PMA) proportion of macrophages isolated from inflamed colonic mucosa were able to undergo respiratory burst. Studies with normal and inflamed ileum showed similar results. Stimulation of macrophages isolated from normal colon with interferon- $\gamma$ produced only a small increase in the proportion of cells showing release of oxygen radicals. We conclude that the respiratory burst capacity of majority of macrophages isolated from normal colon and ileum is downregulated and a greater proportion of macrophages isolated from inflamed colon and ileum are able to undergo a respiratory burst.

An activated macrophage is capable of mediating antimicrobial and cytotoxic effects.' The activation process is accompanied by a number of physiological and biochemical changes. These include enhanced secretion of neutral proteases, ${ }^{2}$ acid hydrolases, ${ }^{3}$ enhanced expression of HLA class II molecules, ${ }^{4}$ down regulation of receptors for mannose terminated glycoconjugates ${ }^{56}$ and an enhanced or upregulated respiratory burst. ${ }^{7}$ During a respiratory burst, oxygen is taken up by the cell and enzymatically converted by membrane associated NADPH oxidase to superoxide anion $\left(\mathrm{O}_{2}^{-}\right)$, hydrogen peroxide $\left(\mathrm{H}_{2} \mathrm{O}_{2}\right)$ and hydroxyl radical $\left(\mathrm{OH}^{-}\right)$. A respiratory burst can be triggered by phagocytosis of particles such as zymosan or by soluble surface active agents such as phorbol myristate acetate (PMA) ${ }^{8}$ Some of the reactive metabolites of oxygen (RMO) can be released outside the cell where damage to surrounding cells can occur. ${ }^{410}$

Ulcerative colitis and Crohn's disease are chronic inflammatory disorders of unknown aetiology, and

Address for correspondence: Dr D P Jewell, Gastroenterology UInit, Radcliffe Infirmary, Oxford OX2 6HE.

Accepted for publication 17 February 1989 macrophages are increased in number in the mucosa ${ }^{11}$ of both being especially prominent in granulomata of Crohn's disease. There is increased monocyte turnover $^{12}$ and activation ${ }^{1314}$ in active disease and these cells are likely to be the main source of the intestinal macrophages. Currently, there is very little information on the function of macrophages in normal and inflamed intestine.

In this study, macrophages isolated from histologically normal colon or ileum and from the colon and ileum of patients with active inflammatory bowel disease (IBD) were studied for their ability to undergo a respiratory burst. Opsonised zymosan, phorbol myristate acetate (PMA) and $\mathrm{N}$-formylmethionylleucyl-phenylalanine (FMLP) were used as triggers. Respiratory burst activity was assessed by reduction of nitroblue tetrazolium to formazan..$^{1516}$ In some studies, the effect of interferon-gamma (IFN- $\gamma$ ) and lipopolysaccharide (LPS) on respiratory burst capacity of isolated macrophages was studied.

\section{Methods}

STUDY POPULATION

Patients (10 men, 14 women, age 23-83 years) 
undergoing colonic resection for carcinoma (16), familial polyposis (two), idiopathic constipation (one) or right hemicolectomy for caecal carcinoma (five) were studied.

Thirty two patients ( 18 men, age 14-70 years) with inflammatory bowel disease involving the colon and 12 patients (seven men, age 16-71 years) with ileal Crohn's disease were studied. All patients undergoing intestinal resection for inflammatory bowel disease had active disease. All except two (with colonic Crohn's disease) were receiving intravenous hydrocortisone.

\section{CELL ISOLATION}

Normal mucosa from patients without inflammatory bowel disease was obtained at least $5 \mathrm{~cm}$ from tumour and was macroscopically as well as histologically normal. Inflamed, and in some cases non or minimally inflamed mucosa was studied from ulcerative colitis or Crohn's disease colon or ileum. Mononuclear cells were isolated by a modification of the technique described by Bull and Bookman. ${ }^{17}$

The mucosa was transported in cold $\left(4^{\circ} \mathrm{C}\right) \mathrm{RPMI}$ 1640 (Gibco) and extensively washed with Hanks' Balanced Salt Solution without calcium and magnesium (CMF HBSS; Flow laboratories). 5-10 $\mathrm{mm}$ strips of mucosa were dissected and incubated with $1 \mathrm{mmol}$ dithiothreitol (Sigma) for $20 \mathrm{~min}$ at room temperature (with shaking every five minutes). Epithelial cells were removed by shaking the mucosa with $5 \mathrm{mM}$ EDT A (BDH Chemicals, Poole, England) at $37^{\circ} \mathrm{C}$ followed by washing with CMF-HBSS. This was repeated twice and after the last EDTA step, washing was performed with Hanks Balanced Salt Solution with calcium and magnesium (HBSS; Flow laboratories). The mucosa was then cut into $2 \mathrm{~mm}$ pieces and digested with collagenase (from Clostridium histolyticum; Boehringer Mannheim) at a concentration of $100 \mathrm{mg} / 100 \mathrm{ml}$ culture medium ( $10 \%$ fetal calf serum in RPMI 1640; Gibco) with shaking for three hours at $37^{\circ} \mathrm{C}$. After digestion, the cells were filtered through a $100 \mu$ nylon mesh and extensively washed with HBSS before centrifugation on Ficoll-Paque (Pharmacia) to obtain mononuclear cells. After further washing, the mononuclear cells were resuspended in culture medium. To determine the proportion of macrophages present, cytocentrifuge preparations of the mononuclear cells were made and stained with macrophage specific monoclonal antibody $\mathrm{Y} 1 / 82 \mathrm{~A}^{1 \times 19}$ using the peroxidase technique..$^{20}$

The respiratory burst activity was assayed within two hours of isolation (except when the mononuclear cells were stimulated with IFN- $\gamma$ and LPS). All the media contained $100 \mathrm{U} / \mathrm{ml}$ penicillin, $100 \mu \mathrm{g} / \mathrm{ml}$ streptomycin and $5 \mu \mathrm{g} / \mathrm{ml}$ gentamycin.
TRIGGERS

Phorbol 12-myristate 13-acetate (PMA; Behring Diagnostics) was kept in small aliquots at $-70^{\circ} \mathrm{C}$ in a stock solution of $1 \mathrm{mg} / \mathrm{ml}$ in dimethylsulphoxide (Grade 1, Sigma). An aliquot was thawed immediately before use.

Opsonised zymosan was prepared as previously described."- Zymosan (Sigma, type A) was boiled in water. After washing it was resuspended in HBSS at $20 \mathrm{mg} / \mathrm{ml}$ and stored at $4^{\circ} \mathrm{C}$. Opsonised zymosan was prepared by incubating the stock zymosan with fresh human serum for $30 \mathrm{~min}$ at $37^{\circ} \mathrm{C}$. It was then centrifuged and resuspended at $1 \mathrm{mg} / \mathrm{ml}$ in HBSS. $\mathrm{N}$-formylmethionyl-leucyl-phenylalanine (FMLP) (Sigma) was stored in phosphate buffered saline $(\mathrm{pH} 7)$ at a concentration of $2 \times 10^{-5} \mathrm{M}$ at $4^{\circ} \mathrm{C}$.

DETECTION OF RESPIRATORY BURST ACTIVITY Release of RMO by macrophages in response to the triggers was assessed by reduction of nitroblue tetrazolium (NBT; Sigma) to a deep blue-black formazan reaction product. Nitroblue tetrazolium was dissolved in RPMI at a concentration of $1 \mathrm{mg} / \mathrm{ml}$ and filtered with a $0 \cdot 2 \mu$ filter just before use.

$1.5 \times 10^{\circ}$ intestinal mononuclear cells in $4 \mathrm{ml}$ culture medium were incubated at $37^{\circ} \mathrm{C}$ with $1 \mathrm{ml}$ NBT solution $(1 \mathrm{mg})$ and either PMA at a final concentration of $200 \mathrm{ng} / \mathrm{ml}, 75 \mu \mathrm{g}$ opsonised zymosan (final concentration, $15 \mu \mathrm{g} / \mathrm{ml}$ ) or FMLP at a final concentration of $10^{-7} \mathrm{M}$. Cells stimulated with PMA and FMLP were incubated for 30 minutes and those with opsonised zymosan for 60 minutes. Controls included incubating the cells with culture medium and NBT only or with dimethylsulphoxide, NBT and culture medium. All the cell cultures were shaken at intervals of 15 minutes. Control experiments and those with triggers were performed concomitantly.

At the end of the incubation period, cytocentrifuge preparations (Cytospin 2; Shandon) were made, air dried and fixed in acetone. They were then stored at $-20^{\circ} \mathrm{C}$ before staining.

Cytocentrifuge preparations of mononuclear cells incubated with PMA or FMLP were stained with monoclonal antibody $\mathrm{Y} 1 / 82 \mathrm{~A}$ which is specific for monocytes and macrophages ${ }^{1 \times 14}$ (kindly donated by Dr D Y Mason, John Radcliffe Hospital, Oxford). Preparations of mononuclear cells incubated with zymosan were stained with an anti-HLA-D monoclonal antibody $201521^{22}$ (kindly donated by $\operatorname{Dr}$ S Fuggle, John Radcliffe Hospital).

Staining of the cytocentrifuge preparations was performed using the peroxidase technique."1" Endogenous peroxidase activity was blocked with methanol and hydrogen peroxide. Controls included omitting the primary antibody or using an irrelevant monoclonal antibody. 
In cytocentrifuge preparations of cells incubated with opsonised zymosan, macrophages were considered to be those cells that were HLA-D positive and had phagocytosed the zymosan. For cells incubated with PMA or FMLP, macrophages were considered to be Y1/82A stained cells. Of these populations of macrophages, the percentage (in each cytocentrifuge preparation) showing release of RMO (as shown by blue-black formazan staining) was determined by counting at least 200 macrophages per preparation. All the cytocentrifuge preparations were coded and analyses were performed blind by one investigator (YRM). Results of many of these were confirmed by other investigators (variation less than $10 \%)$.

IFN- $\gamma$ AND LPS STIMULATION

In some experiments, mononuclear cells isolated from normal or inflamed mucosa were stimulated with IFN- $\gamma$ and LPS. The source of IFN- $\gamma$ was supernatant from Chinese hamster ovary cell line (donated by Dr Scott, Wellcome biotech). Its activity was determined by immunoradiometric assay. It was used in a final concentration of $100-1000 \mathrm{U} / \mathrm{ml}$. LPS was from $E$ coli $055: \mathrm{B} 5$ (Sigma) and was used at a concentration of $10 \mu \mathrm{g} / \mathrm{ml}$.

The mononuclear cells (in suspension) were incubated with these stimuli for 42 hours. Respiratory burst activity by the macrophages, in response to PMA, was then determined as described above.

\section{MONOCYTES}

To study the effect of collagenase treatment on respiratory burst activity, peripheral blood monocytes were studied. Venous blood was collected in heparinised tubes and mononuclear cells were isolated by centrifugation on Ficoll-Paque (Pharmacia). 10 ${ }^{7}$ mononuclear cells were shaken with $1 \mathrm{mg} / \mathrm{ml}$ collagenase (in culture medium) at $37^{\circ} \mathrm{C}$ for 3 hours. Monocytes adherent to glass coverslips were obtained from collagenase treated and untreated mononuclear cells by incubation at $37^{\circ} \mathrm{C}$ for 30 minutes. Non-adherent cells were removed by gentle washing with warm $\left(37^{\circ} \mathrm{C}\right) 5 \%$ FCS/RPMI. Coverslips with adherent monocytes were incubated with culture medium, NBT $(1 \mathrm{mg} / \mathrm{ml})$ and PMA (at a final concentration of $200 \mathrm{ng} / \mathrm{ml}$ ) at $37^{\circ} \mathrm{C}$ for 30 minutes. After washing, the coverslips were fixed in $0.1 \%$ gluteraldehyde for 15 minutes, washed and examined by phase contrast microscopy. The percentage of adherent cells undergoing respiratory burst (as shown by blue-black formazan staining) was determined.

STATISTICAL ANALYSIS

Statistical analysis was performed using Wilcoxon's rank-sum test (paired or unpaired as indicated). The analyses were two-tailed. As data were not normally distributed, results are expressed as a median and range.

\section{Results}

The viability of isolated intestinal and peripheral blood mononuclear cells was always $90 \%$ or more assessed by trypan blue exclusion.

Monocytes from three normal, healthy individuals were used to study the effect of collagenase treatment on respiratory burst activity. There was no significant difference in the proportion of collagenase treated or untreated adherent cells that were able to undergo respiratory burst (untreated - mean $82 \%$; collagenase treated - mean $81 \%$ ).

In cytospin preparations of isolated intestinal mononuclear cells from normal and inflamed ileum and colon, there was no significant difference in the proportion of macrophages (identified with monoclonal antibody Y1/82A) present; normal colon: median $13.5 \%$ (range $7-22 \%$ ); IBD colon median $12 \%$ (range 7-21\%); normal ileum $12 \%$ (range 10 $18 \%$ ); ileal Crohn's disease median $14 \%$ (range 10-19\%).

NITROBLUE TETRAZOLIUM REDUCTION BY ISOLATED INTESTINAL MACROPHAGES IN THE ABSENCE OF A TRIGGER

Initially two controls were used. In one the cells were incubated with culture medium and NBT only for one hour and in the other, they were incubated with dimethylsulphoxide in addition to NBT and culture medium. After some experiments, however, no difference between these two controls were observed (data not shown). Therefore in subsequent experiments, only the control with dimethylsulphoxide was used.

In the absence of a trigger, there was a significant $(p<0.05)$ increase in the proportion of macrophages isolated from inflamed colonic and ileal mucosa that reduced NBT compared with those isolated from mucosa of normal colon and terminal ileum (Fig. 1).

RESPIRATORY BURST ACTIVITY OF ISOLATED

INTESTINAL MACROPHAGES IN RESPONSE TO OPSONISED ZYMOSAN

Preliminary studies using varying doses and time intervals showed that $15 \mu \mathrm{g} / \mathrm{ml}$ of opsonised zymosan incubated for one hour gave optimal results for mononuclear cells obtained from both normal and inflamed mucosa.

In cytocentrifuge preparations, $75-90 \%$ of HLA-D positive macrophages (as assessed by their morphology) had phagocytosed zymosan. There was no difference between normal and inflamed intestine 


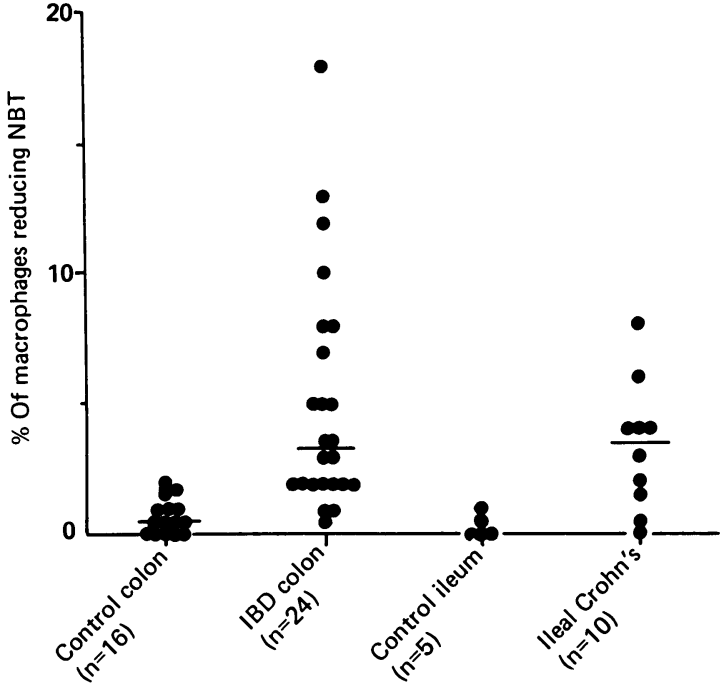

Fig. 1 Percentage of macrophages reducing NBT in the absence of any trigger. Isolated intestinal mononuclear cells were incubated with NBT, culture medium and dimethylsulphoxide only. Cytocentrifuge preparations were then made and the proportion of macrophages ( $Y 1 / 82 \mathrm{~A}$ positive) reducing $N B T$ was determined.

(data not given). These cells were easy to identify and of these, the percentage undergoing respiratory burst as shown by deep blue black staining was determined (Fig. 2).

Only a small proportion of macrophages isolated from normal colon were able to undergo a respiratory burst (median $8 \%$; range $2-33 \%$ ). A significantly

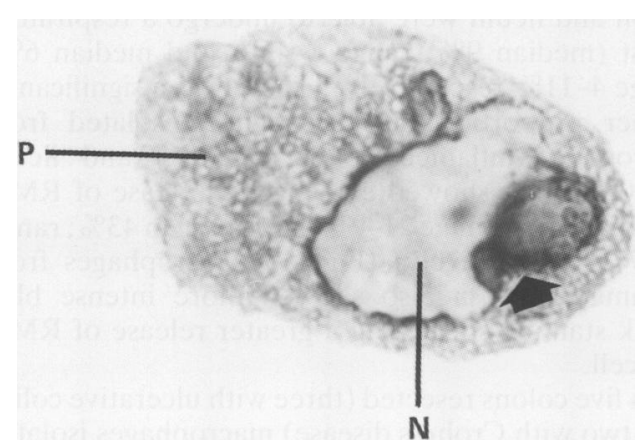

Fig. 2 Isolated intestinal macrophage (stained with antiHLA-D monoclonal antibody, 201521) with a phagocytosed opsonised zymosan particle, showing release of oxygen radicals as shown by the blue black reaction product (arrowed). Nucleus $-N$, peroxidase stain $-P$.

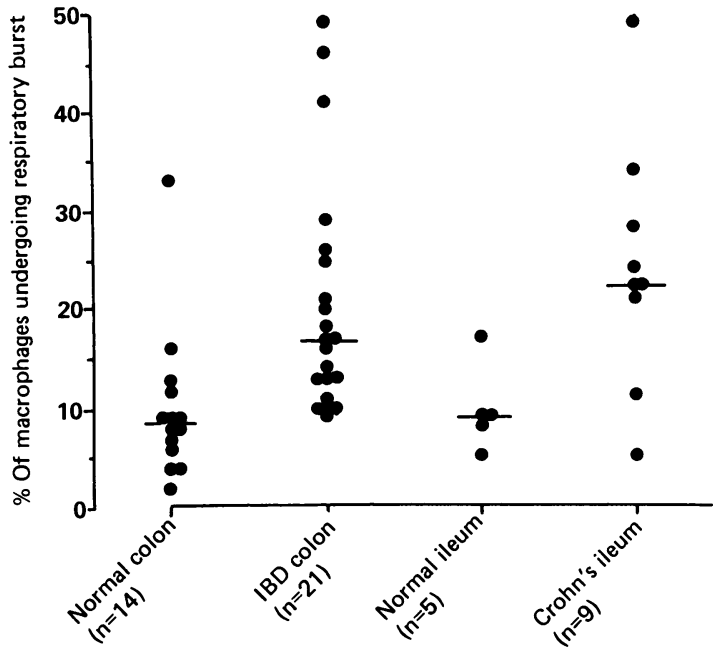

Fig. 3 Percentage of isolated intestinal macrophages undergoing a respiratory burst in response to opsonised zymosan. Intestinal mononuclear cells (in suspension) were incubated with opsonised zymosan and NBT for 60 minutes. Cytocentrifuge preparations were then made and stained with antibody 201521 (anti HLA-D). The proportion of macrophages (HLA-D positive cells with ingested zymosan) showing release of $R M O$ was determined.

greater proportion of macrophages isolated from inflamed colonic mucosa showed evidence of release of RMO (median 17\%; range 9-49\%; p<0.01) (Fig. 3).

Similarly, a significantly greater proportion of macrophages isolated from inflamed mucosa of ileal Crohn's disease showed evidence of having undergone a respiratory burst (median $22 \%$; range $5-49 \%$ ) compared to macrophages isolated from normal terminal ileal mucosa (median $9 \%$; range $5-17 \%$; $\mathrm{p}<0.05)$. There was no difference in the ability of macrophages isolated from different areas of normal colon to release RMO in response to opsonised zymosan (data not shown). There was also no difference between ulceratative colitis and Crohn's disease in the proportion of isolated colonic macrophages able to undergo a respiratory burst.

In six inflammatory bowel disease colons resected (four with ulcerative colitis and two with Crohn's disease), it was possible to study from the same colon, macrophages isolated from inflamed as well as from areas which were normal or near normal macroscopically and histologically. In five of six colons, fewer macrophages isolated from non or minimally inflamed mucosa showed evidence of release of RMO compared with those isolated from severely inflamed areas. In the sixth colon, no difference was seen (Fig. 4). 

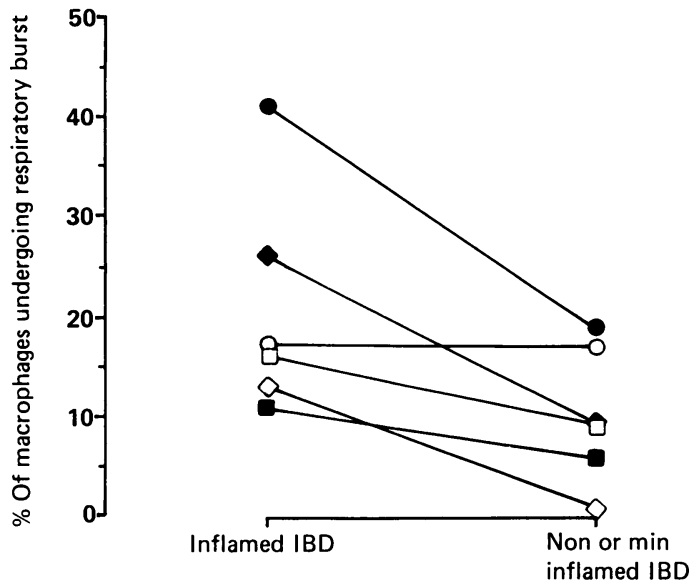

Fig. 4 Respiratory burst activity of macrophages isolated fron non or minimally inflamed areas of six IBD colons. Opsonised zymosan was the trigger used. Proportion of macrophages (HLA-D positive with ingested zymosan) reducing $N B T$, in cytocentrifuge preparations, was determined (different symbols indicate separate patients).

RESPIRATORY BURST ACTIVITY OF ISOLATED INTESTINAL MACROPHAGES IN RESPONSE TO PMA

Macrophages were easy to identify with the monoclonal antibody $\mathrm{Y} 1 / 82 \mathrm{~A}$ (giving a brown reaction

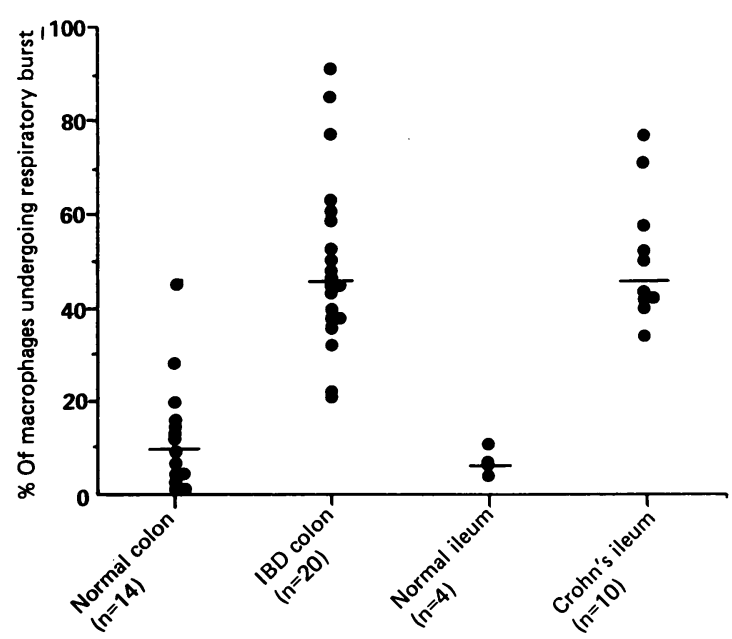

Fig. 5 Percentage of isolated intestinal macrophages undergoing a respiratory burst in response to PMA. Intestinal mononuclear cells (in suspension) were incubated with PMA and NBT for 30 minutes. Cytocentrifuge preparations were then made and stained with monoclonal antibody YI/82A. The proportion of macrophages (YI/82A positive) reducing $N B T$ was determined.
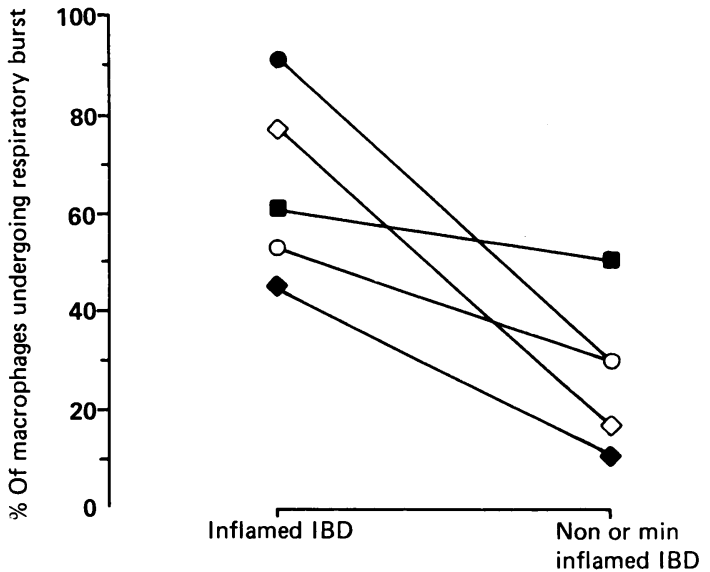

Fig. 6 Respiratory burst activity of macrophages isolated from inflamed and non or minimally inflamed areas of five IBD colons. PMA was used as a trigger. Proportion of macrophages (YI/82A positive) reducing $N B T$, in cytocentrifuge preparations was determined (different symbols represent separate patients).

product) and the proportion releasing RMO (blue black staining) was determined. Studies using another macrophage specific monoclonal antibody $3 \mathrm{C} 10^{211}$ gave similar results to those obtained with $\mathrm{Y} 1 /$ $82 \mathrm{~A}$ (data not shown). The latter was chosen because of good and consistent staining using the peroxidase technique. In this system, contaminating polymorphs and eosinophils could be ignored as they did not stain with the monoclonal antibody (endogenous peroxidase activity having been blocked).

As was found for opsonised zymosan, only a small proportion of macrophages isolated from normal colon and ileum were able to undergo a respiratory burst (median $9 \%$; range $1-45 \%$ and median $6 \%$; range $4-11 \%$ respectively). There was a significantly higher proportion of macrophages isolated from mucosa of inflamed colon $(p<0.01)$ and ileum $(p<0.01)$ that showed evidence of release of RMO (median $45 \%$; range $21-91 \%$ and median $43 \%$; range 34-77\% respectively) (Fig. 5). Macrophages from inflamed mucosa also showed more intense blue black staining suggesting a greater release of RMO per cell.

In five colons resected (three with ulcerative colitis and two with Crohn's disease) macrophages isolated from severely inflamed and non or minimally inflamed areas of the same colon were studied (Fig. 6). In all five, a greater proportion of macrophages isolated from severely inflamed mucosa showed evidence of release of RMO compared with those from non or minimally inflamed mucosa. 


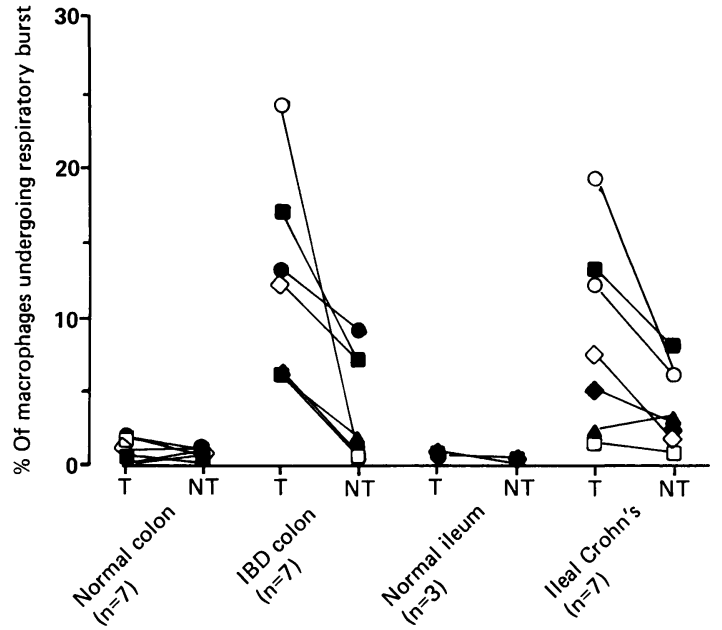

Fig. 7 Respiratory burst activity of isolated colonic macrophages in the presence (T) or absence (NT) or FMLP. Isolated intestinal mononuclear cells (in suspension) were incubated with NBT and with or without FMLP for 30 minutes. Cytocentrifuge preparations were then made and the proportion of macrophages (YI/82A positive) showing release of $R M O$ was determined (different symbols represent separate patients). Normal colon: FMLP v no trigger - p: not significant; Normal ileum: FMLP $\mathrm{v}$ no trigger - $p$ : not significant; IBD colon: FMLP $\vee$ no trigger $-p<0 \cdot 01$; Ileal Crohn's: FMLP v no trigger $-p<0.05$ (paired Wilcoxon's rank-sum test); FMLP: normal colon $\vee I B D$ colon $-p<0 \cdot 01$; FMLP: normal ileum v ileal Crohn's $-p<0.05$; (unpaired Wilcoxon's rank-sum test)

RESPIRATORY BURST ACTIVITY OF ISOLATED INTESTINAL MACROPHAGES IN RESPONSE TO FMLP

Preliminary studies showed that $10^{-7} \mathrm{M}$ of FMLP was optimal for triggering the respiratory burst (data not shown). N-formylmethionyl-leucyl-phenylalanine was not able to trigger macrophages isolated from normal colon and ileum to undergo a respiratory burst (Fig. 7). For macrophages isolated from inflamed ileal and colonic mucosa, FMLP was much less potent at triggering respiratory burst activity than opsonised zymosan or PMA. This was shown by a smaller proportion of cells isolated from inflamed mucosa demonstrating release of RMO as well as much less intense blue black staining per cell.

RESPIRATORY BURST ACTIVITY OF ISOLATED INTESTINAL MACROPHAGES AFTER STIMULATION WITH IFN- $\gamma$ OR LPS In preliminary studies, IFN- $\gamma$ at a concentration of $680 \mathrm{U} / \mathrm{ml}$ was optimal for stimulating intestinal macrophages to undergo a respiratory burst. The viability of the mononuclear cells at the end of the
Table Respiratory burst activity of isolated intestinal macrophages following incubation with LPS and/or IFN- $\gamma$. The intestinal mononuclear cells were incubated (in suspension) with LPS, IFN- $\gamma$ or culture medium only at $37^{\circ} \mathrm{C}$ for $42 \mathrm{~h}$. PMA and NBT were then added and the cells incubated for a further 30 minutes. Cytocentrifuge preparations were then made and stained with monoclonal antibody YI/82A. Percentage of macrophages (YI/82A positive) undergoing a respiratory burst was then determined.

\begin{tabular}{|c|c|c|c|c|c|}
\hline & & $\begin{array}{l}\text { Culture } \\
\text { medium } \\
\text { only }\end{array}$ & $\begin{array}{l}L P S \\
I 0 \mathrm{ug} / \mathrm{ml}\end{array}$ & $\begin{array}{l}I F N-\gamma \\
680 U / m l\end{array}$ & $\begin{array}{l}I F N-\gamma \\
+L P S\end{array}$ \\
\hline \multicolumn{6}{|l|}{ Normal } \\
\hline & 1 & 29 & 28 & 58 & \\
\hline & 2 & 32 & 29 & 40 & \\
\hline & 3 & 15 & 16 & 21 & 22 \\
\hline & 4 & 6 & 7 & 12 & 11 \\
\hline \multicolumn{6}{|l|}{ IBD } \\
\hline colon & 1 & 39 & 35 & 42 & \\
\hline & 2 & 62 & 6.3 & 65 & \\
\hline & 3 & 74 & 77 & 80 & \\
\hline & 4 & 83 & 86 & 87 & \\
\hline & 5 & 50 & 47 & 53 & \\
\hline
\end{tabular}

incubation period (with IFN- $\gamma$ or LPS) was always $80 \%$ or more.

Incubating the mononuclear cells in the presence or absence of IFN- $\gamma$ or LPS did not influence the proportion of macrophage staining with Y1/82A (data not shown).

After incubation with IFN- $\gamma$ there was a small increase in the proportion of macrophages from normal colonic mucosa that showed evidence of release of RMO (Table). Stimulation with LPS did not make any significant difference. In two experiments the mononuclear cells were incubated with IFN- $\gamma$ and LPS, however the proportion of macrophages showing release of RMO was similar to that after incubation with IFN $\gamma$ alone. Incubating mononuclear cells isolated from inflamed mucosa with either IFN- $\gamma$ or LPS did not produce any significant change in the proportion of macrophages undergoing a respiratory burst (Table).

\section{Discussion}

In the human ileum and colon macrophages are found in the lamina propria and are most prominent close to the basement membrane of the epithelium..$^{2+}$ Studies in our unit have shown morphological and immunohistochemical heterogeneity of these cells in normal and inflamed ileum and colon ${ }^{25}$ in as well as in the granulomata of Crohn's disease. ${ }^{27}$ There is little information on the functions of these intestinal cells. ${ }^{2 x}$

This study investigated the capacity of isolated 
intestinal macrophages to undergo a respiratory burst as shown by the reduction of NBT to a deep blue black formazan reaction product in response to various triggers. This test gives a semiquantitative measure of respiratory burst activity in individual cells. ${ }^{1624}$

Superoxide anion, hydrogen peroxide and hydroxyl radicals can be more accurately determined quantitatively. ${ }^{\times}$These assays were not performed in this study because of difficulties in consistently excluding polymorphonuclear leucocyte contamination especially from mononuclear suspensions isolated from inflamed mucosa. In preliminary studies varying degrees of polymorphonuclear leucocyte contamination occurred despite centrifugation on Ficoll-Paque (performed twice) and separation of cells by adherence to fibronectin coated plates. This may reflect properties of young polymorphonuclear cells recruited into the mucosa. Any quantitative analysis of RMO in the presence of contaminating polymorphonuclear leucocytes would not accurately reflect production of these radicals by the macrophages.

The technique (NBT reduction) used in this study allows examination of most of the macrophage population rather than that selected - for example, by adherence or elutriation. In addition, this technique also enables study of the relationship of macrophage phenotype (as determined by monoclonal antibody or histochemical staining) and the functional capacity of the cell to release RMO. Our own and previous studies $^{25}{ }^{30131}$ have shown that most of the human intestinal macrophages express MHC class II molecules. Our studies have also shown that most of these cells also stain with monoclonal antibody Y1/82A. ${ }^{2 n}$ Using two different ways to define the macrophage population and using different triggers, we have shown that a greater proportion of macrophages isolated from the mucosa of ulcerative colitis and Crohn's disease are able to undergo a respiratory burst compared with those isolated from normal terminal ileal or colonic mucosa.

During a respiratory burst, superoxide anion is formed by one-electron reduction of oxygen, a reaction catalysed by membrane-associated NADPH oxidase. In activated macrophages, this response is enhanced.' Using this criteria, it appears that only a small proportion of normal intestinal macrophages are activated and that this proportion is increased in inflamed mucosa. As majority of human intestinal macrophages express HLA class II molecules, ${ }^{31131}$ however it has been suggested that they are all activated.3: These differences may reflect heterogeneity in the activation of the macrophages. It is also possible that the intestinal macrophages express HLA-DR because they may be frequently required to present antigen to $\mathrm{T}$ Cells but are not activated as assessed by other functional tests.

It has been postulated that as monocytes migrate and mature into tissue macrophages, their ability to secrete large amounts of superoxide and hydrogen peroxide may be down regulated. ${ }^{33}$ This is supported by in vitro studies of superoxide anion and hydrogen peroxide production by monocytes after isolation and during differentiation into macrophages. ${ }^{3 .}$

IFN- $\gamma$ has been shown to activate macrophage oxidative metabolism. 'After stimulation with IFN- $\gamma$, one would have expected majority of the macrophages from normal colonic mucosa to be able to undergo a respiratory burst (in the presence of PMA). Only a small proportion were able to do so, however, suggesting that the resident population of intestinal macrophages in the normal colon are 'desensitised' to the effect of IFN- $\gamma$. The activity of this batch of IFN- $\gamma$ had previously been determined and it has also been shown to induce HLA-DR in an epithelial cell line. ${ }^{3+}$ The possibility that the 'desensitisation' to IFN- $\gamma$ may be caused by the presence of tumour in the resected specimen cannot be excluded. One of the patients studied, however, had intestinal resection for idiopathic constipation, suggesting that this 'desensitisation' may be a phenomenon of normal intestinal macrophages.

This effect may be mediated by trace levels of bacterial lipopolysaccharide. ${ }^{35}$ In this respect, intestinal macrophages may have some similarities to murine Kupffer cells which fail to respond to IFN- $\gamma$ in vitro with a rise in their respiratory burst activity. ${ }^{36}$ Both may be exposed to trace levels of LPS which may cross the bowel wall into the portal circulation under physiological conditions. ${ }^{37}$ It is also possible that the lack of respiratory burst by these cells under normal conditions, protects from oxidative injury. ${ }^{3 \times}$

In active inflammatory bowel disease, there is infiltration by polymorphonuclear leucocytes, lymphocytes and macrophages. " The greater proportion of intestinal macrophages from inflammatory bowel disese mucosa that are able to undergo a respiratory burst may be either the result of an upregulation of respiratory burst capacity of the resident population of cells or may reflect an elicited population of macrophages. It is generally believed that tissue macrophages in inflammatory lesions are predominantly derived from blood monocytes..$^{39}$ Our studies with IFN- $\gamma$ suggest that it is probably the elicited population of macrophages (derived from circulating monocytes) that contribute to the increased proportion able to release RMO.

Oxygen radicals produced by activated macrophages (as well as polymorphonuclear leucocytes) may be involved in mediating damage in the inflamed mucosa." The oxygen metabolites are likely to be 
generated by phagocytosis of bacterial and other products penetrating into the mucosa because of a breach in the epithelial barrier. Chemotactic peptides like FMLP ${ }^{+1}$ may also play a role. Apart from superoxide anion $\left(\mathrm{O}_{2}\right)$, hydrogen peroxide $\left(\mathrm{H}_{2} \mathrm{O}_{2}\right)$ and hydroxyl radical $\left(\mathrm{OH}^{*}\right)$, other oxygen metabolites that may be involved in tissue damage are hypohalides. Hypochlorite $\left(\mathrm{OCI}^{-}\right)$is one of the main hypohalides and is formed through the activity of the azurophilic granule enzyme myeloperoxidase." Oxygen radicals may intereact with proteinases secreted by the same phagocytic cells." Thus local inactivation of antiproteinases by $\mathrm{RMO}^{42}$ may allow local uncontrolled action of enzymes secreted by phagocytes. Oxygen radicals may also denature proteins and make them susceptible to proteinases. ${ }^{+3}$

Dr Mahida was supported by the Medical Research Council. We are grateful to Dr Siamon Gordon (Sir William Dunn School of Pathology) for his helpful advice and to Mr Kettlewell and Mr Mortensen for the operation resection specimens.

\section{References}

1 Adams DO, Hamilton TA. The cell biology of macrophage activation. Ann Rev Immunol 1984; 2: 283-318.

2 Johnson WJ, Pizzo SV, Imber MJ, Adams DO. Receptors for maleated proteins regulate the secretion of neutral proteases by murine macrophages. Science 1982 ; 218: $574-6$.

3 Bonney RJ, Davies P. Possible autoregulatory functions of the secretory products of mononuclear phagocytes. Contemp Top Immunobiol 1984; 13: 199-223.

4 Unanue $R$. The regulatory role of macrophages in antigenic stimulation. Part II. Symbiotic relationship between lymphocytes and macrophages. Acta Immunol 1981; 31: 1 .

5 Ezckowitz RAB, Gordon S. Down-regulation of mannosyl receptor mediated endocytosis and antigen $\mathrm{F} 4 / 80$ in Bacillus Calmette-Guerin-activated mouse macrophages Role of T lymphocytes and lymphokines. $J$ Exp Med 1982; 155: 1623-37.

6 Mokocna T, Gordon S. Human macrophage activation. Modulation of mannosyl, fucosyl receptor activity in vitro by lymphokines, gamma and alpha interferons and dexamethazone. J Clin Invest 1985; 75: 415-32.

7 Nathan CF, Murray HW, Wiebe ME, Rubin BY. Identification of interferon-gamma as the lympokine that activates human macrophage oxidative metabolism and antimicrobial activity. $J$ Exp Med $1983 ; 158$ : 670-89.

8 Badeway JA, Robinson JM, Karnovsky MJ, Karnovsky ML. Reduction and excitation of oxygen by phagocytic leucocytes: biochemical and cytochemical techniques. In: Weir DM, Herzenberg LA, Blackwell C. Handbook of experimental immunology. 2. Cellular immunology. Oxford: Blackwell, 1986: 50: 1-50.6.

9 Henson PM, Johnson RB. Tissue injury in inflammation. J Clin Invest 1987; 79:669-74.

10 Weiss SJ, LoBuglio AF. Phagocyte-generated oxygen metabolites and cellular injury. Lab Invest 1982; 47: 5-18.

11 Strober W, James SP. The immunological basis of inflammatory bowel disease. J Clin Immunol 1986; 6: 415-32.

12 Meuret G, Bitzi A, Hammer GB. macrophage turnover in Crohn's disease and ulcerative colitis. Gastroenterology 1978; 74: 501-3.

13 Mee AS, Szawatakowski M. Jewell DP. Monocytes in inflammatory bowel disease: phagocytosis and intracellular killing. J Clin Pathol 1980; 33: 921-25.

14 Doc WF, Forsman B. Chronic inflammatory bowel disease: increased plasminogen activator secretion by mononuclear phagocytes. Clin Exp Immunol 1982; 48: 256-60.

15 Nathan DG, Baehner RL, Weaver DK. Failure of nitroblue tetrazolium reduction in the phagocytic vacuoles of leukocytes of chronic granulomatous disease. J Clin Invest 1969; 48: 895-904.

16 Ezekowitz RAB, Orkin SH, Newburger PE. Recombinant interferon gamma augments phagocyte superoxide production and $\mathrm{x}$-chronic granulomatous disease gene expression in $x$-linked variant chronic granulomatous disease. J Clin Invest 1987; 80: 1009-16.

17 Bull DM, Brookman MA. Isolation and functional characterization of human intestinal mucosal lymphoid cells. J Clin Invest 1977; 59: 966-74.

18 Hogg N, Horton MA. Myeloid antigens: new and previously defined clusters. In: McMichael AJ, ed. Leucoyte typing III. White cell differentiation antigens. Oxford: Oxford University Press, 1987: 576-602.

19 Davey FR, Cordell JL, Erber WN, Pulford KAF, Gatter KC, Mason DY. Monoclonal antibody (Y1/82A) with specificity towards peripheral blood monocytes and tissue macrophages. J Clin Pathol 1988; 41: 753-8.

20 Gatter KC, Falinia B, Mason DY. The use of monoclonal antibodies in histopathological diagnosis. In: Anthony PP. MacSween NM. eds. Recent advances in histopathology. Vol 12. Edinburgh: Churchill Livingstone, 1984: 135-67.

21 Berton G, Gordon S. Superoxide release by peritoneal and bone marrow derived mouse macrophages. Modulation by adherence and cell activation. Immunology 1983; 49: 693-705.

22 Smith KGC, Austyn JM, Harris G, Beverley PCL, Morris MJ. T cell activation by anti-T3 antibodies: comparison of $\mathrm{IgG} 1$, and $\mathrm{IgG} 2 \mathrm{~b}$ switch variants and direct evidence for accessory function of macrophage $\mathrm{Fc}$ receptors. Eur J Immunol 1986; 16: 478-86.

23 Van Voorhis WC. Steinman RM. Hair LS. et al. Specific antimononuclear phagocyte monoclonal antibodies. Application to the purification of dendritic cells and the tissue localization of macrophages. J Exp Med 1983; 158: $126-45$.

24 Donnellan WL. The structure of the colonic mucosa. The epithelium and subepithelium reticulohistiocytic complex. Gastroenterology 1965; 49: 496-514.

25 Selby WS, Poulter LW, Hobbs S, Jewell DP, Janossy G. Heterogeneity of HLA-DR-positive histiocytes in human intestinal lamina propria: a combined histochemical and immunohistological analysis. J Clin Pathol 1983: 36: 379-84. 
26 Mahida YR, Gionchetti P, Vaux D, Patel S, Jewell DP. Macrophage subpopulations in lamina propria of normal and inflamed colon and terminal ileum. Gut 1989: 30: 826-34.

27 Mahida YR, Patel S, Wu K, Jewell DP. Macrophage and lymphoid subpopulations in the granulomata of Crohn's disease. [Abstract]. Gut 1987; 28: A1388.

28 Verspaget H. Becken W. Mononuclear phagocytes in the gastrointestinal tract. Acta Chir Scand 1985; 525 [Suppl] 113-26.

29 Ezckowitz RAB, Sim RB, MacPherson GG, Gordon S. Interaction of human monocytes, macrophages and polymorphonuclear leukocytes with zymosan in vitro. Role of type 3 complement receptors and macrophagederived complement. J Clin Invest 1985; 76: 2368-76.

30 Becken W, Miereme Ooms M, Ginsel IA, Leith PCJ, Verspaget $H$. Enrichment of macrophages in cell suspensions of human intestinal mucosa by elutriation centrifugation. J Immunol Methods 1984; 73: 189-201.

31 Golder JP, Doe WF. Isolation and preliminary characterization of human intestinal macrophages. Gastroenterology 1983; 84: 795-802.

32 Mowat AM. The cellular basis of gastrointestinal immunity. In: Marsh MN, ed. Immunopathology of the small intestine. Chichester: John Wiley, 1987: 41-72.

33 Nakagawara A, Nathan CF, Cohn ZA. Hydrogen peroxide metabolism in human monocytes during differentiation in vitro. J Clin Invest 1981; 68: 1243-52.

34 Lowes JR, Radwan P, Priddle JD, Jewell DP. Induction of HLA-DR molecules on a colonic epithelial cell line by gamma-interferon [Abstract]. Clin Sci 1987; 74: [suppl no 18$]$ : 31 .

35 Ding AH, Nathan CF. Trace levels of bacterial lipopolysaccharide prevent interferon-gamma or tumour necrosis factor-alpha from enhancing mouse peritoneal macrophage respiratory burst capacity. J Immunol 1987; 139: 1971-77.

36 Lepay DA, Nathan CF, Steinman RM, Murray HW, Cohn ZA. Murine Kupffer cells. Mononuclear phagocytes deficient in generation of reactive oxygen intermediates. J Exp Med 1985; 161: 1079-84.

37 Mathison JC, Ulevitch RJ. The clearance, tissue distribution, and cellular localization of intravenously injected lipopolysaccharide in rabbits. J Immunol 1979; 123: 2133.

38 Gordon S, Crocker PR, Morris L, Lee SH, Perry HV, Hume DA. Localization and function of tissue macrophages. In: Biochemistry of macrophages. Ciba Foundation Symposium 118. Chichester: John Wiley, 1986: 54-62.

39 Anonymous. Bone marrow origin of Kuppfer cells. [Editorial]. Lancet 1980; i: 131-2.

40 Hobson $\mathrm{CH}$, Butt TJ, Ferry DM, Hunter J, Chadwick VS, Broom MF. Enterohepatic circulation of bacterial chemotactic peptide in rats with experimental colitis. Gastroenterology 1988; 94: 1006-13.

41 Klebanoff SJ. Myeloperoxidase: contribution to the microbicidal activity of intact leukocytes. Science 1970; 169: $1095-7$.

42 Carp H, Janoff A. In vitro suppression of serum clastase-inhibitory capacity by reactive oxygen species generated by phagocytosing polymophonuclear leukocytes. J Clin Invest 1979; 63: 793-7.

43 Fligiel SE, Lee EC, McCoy JP, Johnson KJ, Vavani J. Protein degradation following treatment with hydrogen peroxide. Am J Pathol 1984; 115: 418-25. 